\title{
Confirmação da ocorrência de Rumex cuneifolius Campd. (Polygonaceae) no Brasil
}

\author{
Francisco José Machado Caporal ${ }^{1,3}$, Adriana Guglieri-Caporal ${ }^{1}$ e Efigenia de Melo $^{2}$
}

Recebido: 21.10.2010; aceito: 5.05.2011

\begin{abstract}
Confirmation of occurrence of Rumex cuneifolius Campd. (Polygonaceae) in Brazil). Rumex cuneifolius is native from Peru, Bolivia, Chile, Argentina and Uruguay, and introduced in North America, Europe and Australia due to its medicinal potential, and edible and forage qualities. The species was cited for São Paulo in Flora Brasiliensis, but there is no record in herbaria of that state. Its occurrence in Brazil was recently confirmed in Rio Grande do Sul, based on a population found in rural area of Canguçu. For this work we performed review of literature and regional herbaria, collection of specimens, observed populations in field and studied the external morphology of R. cuneifolius. The species is recognized by oboval-lanceolate leaves, inflorescences without foliaceous bracts and fruits with valves with entire margin and well developed callus oblong on the three wings. In Rio Grande do Sul it occurs in ruderal areas.
\end{abstract}

Key words: Brazil, língua-de-vaca, Rumex cuneifolius.

RESUMO - (Confirmação da ocorrência de Rumex cuneifolius Campd. (Polygonaceae) no Brasil). Rumex cuneifolius é nativa do Peru, Bolívia, Chile, Argentina e Uruguai e introduzida na América do Norte, Europa e Austrália devido aos seus potenciais medicinal, comestível e forrageiro. A espécie foi indicada para São Paulo na Flora Brasiliensis, mas não há registro em herbários daquele Estado. Sua ocorrência no Brasil foi recentemente confirmada no Rio Grande do Sul com base em uma população encontrada na área rural de Canguçu. Para o trabalho, foram realizadas revisão bibliográfica e de herbários regionais, coleta de espécimes, observação de populações no campo e estudos exomorfológicos. A espécie é reconhecida pelas folhas oboval-lanceoladas, pelas inflorescências sem brácteas foliáceas e pelos frutos, com valvas de margem inteira e calos oblongos muito desenvolvidos nas três alas. No Rio Grande do Sul, ocorre em áreas ruderais.

Palavras-chave: Brasil, língua-de-vaca, Rumex cuneifolius.

\section{Introdução}

O gênero Rumex L. (Polygonaceae) inclui cerca de 100 espécies de ampla distribuição em ambos os hemisférios, mas pobremente representadas na região tropical (Melo \& Marcondes-Ferreira 2009).

Rumex cuneifolius Campd. é nativa do Peru, Bolívia, Chile, Argentina e Uruguai (Rechinger 1937, Lousley 1953, Cabrera 1967) onde ocorre sobre solos arenosos, geralmente em áreas de dunas costeiras, margens de rios e borda de matas, desde o nível do mar até $3.800 \mathrm{~m}$ de altitude nos Andes Boliviano e Peruano (Rechinger 1990). Foi introduzida na América do Norte, Europa e Austrália (Rechinger 1937, Mosyakin 2005), provavelmente, devido ao seu potencial medicinal (Del Vitto et al. 1997, Macía et al. 2005, Goleniowski et al. 2006), comestível (INTA 2003) e/ou forrageiro para ovinos (Robles et al. 2001).

Cabrera (1967) indicou $R$. cuneifolius para o Brasil, e Meisner (1855) na Flora Brasiliensis mencionou sua ocorrência na "Prov. S. Pauli", atual Estado de São Paulo. Entretanto a espécie não foi registrada em nenhuma flora regional, tampouco há exemplares da espécie nos herbários de São Paulo, que foram revisados pela terceira autora na elaboração da Flora Fanerogâmica do Estado de São Paulo.

1. Universidade Federal de Mato Grosso do Sul, Centro de Ciências Biológicas e da Saúde, Laboratório de Botânica, Cidade Universitária, Caixa Postal 549, 79070-900 Campo Grande, MS, Brasil

2. Universidade Estadual de Feira de Santana, Departamento de Ciências Biológicas, Laboratório de Taxonomia Vegetal, Campus Universitário, BR 116 Norte, km 3, Caixa Postal 294, 44031-460 Feira de Santana, BA, Brasil

3. Autor para Correspondência: franciscocaporal@ig.com.br 
O presente trabalho relata o primeiro registro de $R$. cuneifolius para o Brasil com base em uma população localizada na área rural do município de Canguçu, Rio Grande do Sul, não havendo, porém, informações concretas sobre a origem da espécie na região. Estão sendo apresentados breve descrição taxonômica, informações sobre distribuição geográfica, ecologia e fenologia, além de meios para identificação da espécie.

\section{Material e métodos}

Para o trabalho, foram realizadas revisões bibliográficas e dos principais herbários do Rio Grande do Sul (ICN, HAS, MPUC e PACA, siglas conforme Holmgren et al. 1990), coleta de espécimes, observação da população no campo e estudos exomorfológicos para elaboração de chave e descrição taxonômica.

As ilustrações foram feitas à mão-livre com o auxílio de estereomicroscópio Leica L2; a prancha foi coberta a nanquim em papel vegetal e digitalizada.

Os exemplares coletados estão depositados no herbário CGMS da Universidade Federal de Mato Grosso do Sul campus Campo Grande.

\section{Resultados e Discussão}

\section{Rumex L.}

Ervas ou subarbustos anuais ou perenes, monóicos, dióicos ou polígamos, caule com medula maciça. Pecíolo curto ou longo; ócrea cilíndrica, membranácea, hialina, escariosa. Folhas basais e caulinares frequentemente distintas, as basais maiores; lâmina lanceolada, linear-lanceolada ou oblonga, ápice longo-atenuado ou agudo, base obtusa, aguda, arredondada ou subcordada, margem inteira, ondulada. Inflorescência em panícula, racemo ou fascículo, axilar ou terminal. Flores dispostas em fascículos bracteados, bissexuadas ou unissexuadas, com ou sem rudimento de sexo abortado. Perianto com 2 séries de 3 tépalas livres ou parcialmente unidas na base, as externas menores que as internas (nas flores bissexuadas ou pistiladas) ou idênticas (nas flores estaminadas); estames 6, filetes curtos, anteras basifixas; ovário tricarpelar, estilete trífido, estigmas plumosos ou fimbriados, óvulo 1, placentação basal. Fruto diclésio, perianto frutífero membranáceo, acrescente; endosperma não ruminado.

Gênero com ca. 100 espécies distribuídas em ambos hemisférios, mas pobremente representadas nas regiões tropicais (Melo \& Marcondes-Ferreira 2009). Para o Brasil foram citadas cinco espécies (Melo 2010) e pelo presente trabalho está sendo confirmada a ocorrência de $R$. cuneifolius.

Os frutos maduros apresentam um tecido esponjoso composto por aerênquima que se desenvolve externamente sobre o verticilo interno após a frutificação. Esse intumescimento forma uma protuberância sobre a nervura central, denominada "calo". O calo pode se desenvolver sobre uma ou três alas, sendo característico para cada espécie e um importante caráter para reconhecimento e diferenciação dos representantes do gênero.

Chave para as espécies de Rumex ocorrentes no Brasil

1. Lâminas foliares de base hastada; fruto sem calos sobre as valvas Rumex acetosella

1. Lâminas foliares de base aguda, obtusa, atenuada, subarredondada, truncada ou cordada; fruto com calos desenvolvidos sobre as valvas

2. Perianto frutífero de margem denteada ou fimbriada Rumex obtusifolius

2. Perianto frutífero de margem inteira

3. Valvas ovais ou cordadas, calos arredondados menores que as valvas Rumex crispus

3. Valvas triangulares, calos alongados subiguais, maiores ou menores que as valvas

4. Calos menores que as valvas Rumex sellowianus

4. Calos maiores ou subiguais as valvas

5. Inflorescências com brácteas foliáceas bem desenvolvida Rumex brasiliensis

5. Inflorescências sem brácteas foliáceas, ou se presentes, pouco desenvolvidas 
Rumex cuneifolius Campd., Monogr. Rumex: 95. 1819.

Figuras 1 a-f

Erva ou subarbusto perene, monóico; rizoma horizontal ramificado, ramos aéreos eretos, 30-40(-90) cm alt., glabros, entrenós 2-7 cm compr., estriados. Pecíolo 0,5-1,5 cm compr., glabro; ócrea 0,5-1,5(-2,0) cm compr., membranácea, glabra, hialina, lacerada, persistente pela base. Folhas simples, alternas, inteiras, monomórficas; lâminas (1,3-)2-6 × (1,0-)1,5-3 cm, lanceoladas ou obovado-lanceoladas, ápice obtuso, base atenuada, decorrente, membranácea, glabra, margem ligeiramente ondulada, nervuras inconspícuas em ambas as faces. Inflorescência terminal, em tirsos ramificados, sem brácteas foliáceas ou, se presentes, pouco desenvolvidas, cincinos fasciculados, sucessivamente alternados, pedúnculos em dicotomias sucessivas, raque glabra ou pubérula, estriada; ocréolas membranáceas, hialinas, glabras, laceradas; pedicelos 0,5-1 cm compr., articulados na base. Flores unissexuadas, com ou sem rudimento de sexo abortado, actinomorfas, 1-4,8 mm compr., perianto trímero, tepalóide, esverdeado; flores estaminadas não vistas; flores pistiladas com 3 tépalas externas ligeiramente coalescentes na base, glabras, persistentes na frutificação; estigmas fimbriados, estaminódios 6 ou ausentes. Fruto 3-5 mm compr., perianto frutífero com valvas triangulares, membranáceas, margem inteira, calos oblongos, desenvolvidos nas 3 alas.

Material examinado: BRASIL. Rio Grande do Sul: Canguçu, Terceiro Distrito de Canguçu, Coxilha do Fogo, Cabanha Sobrado Branco, 5-II-2004, F.J.M. Caporal 300 (CGMS); idem, 5-II-2004, F.J.M. Caporal 301 (CGMS); idem, 5-II-2004, F.J.M. Caporal 302 (CGMS).

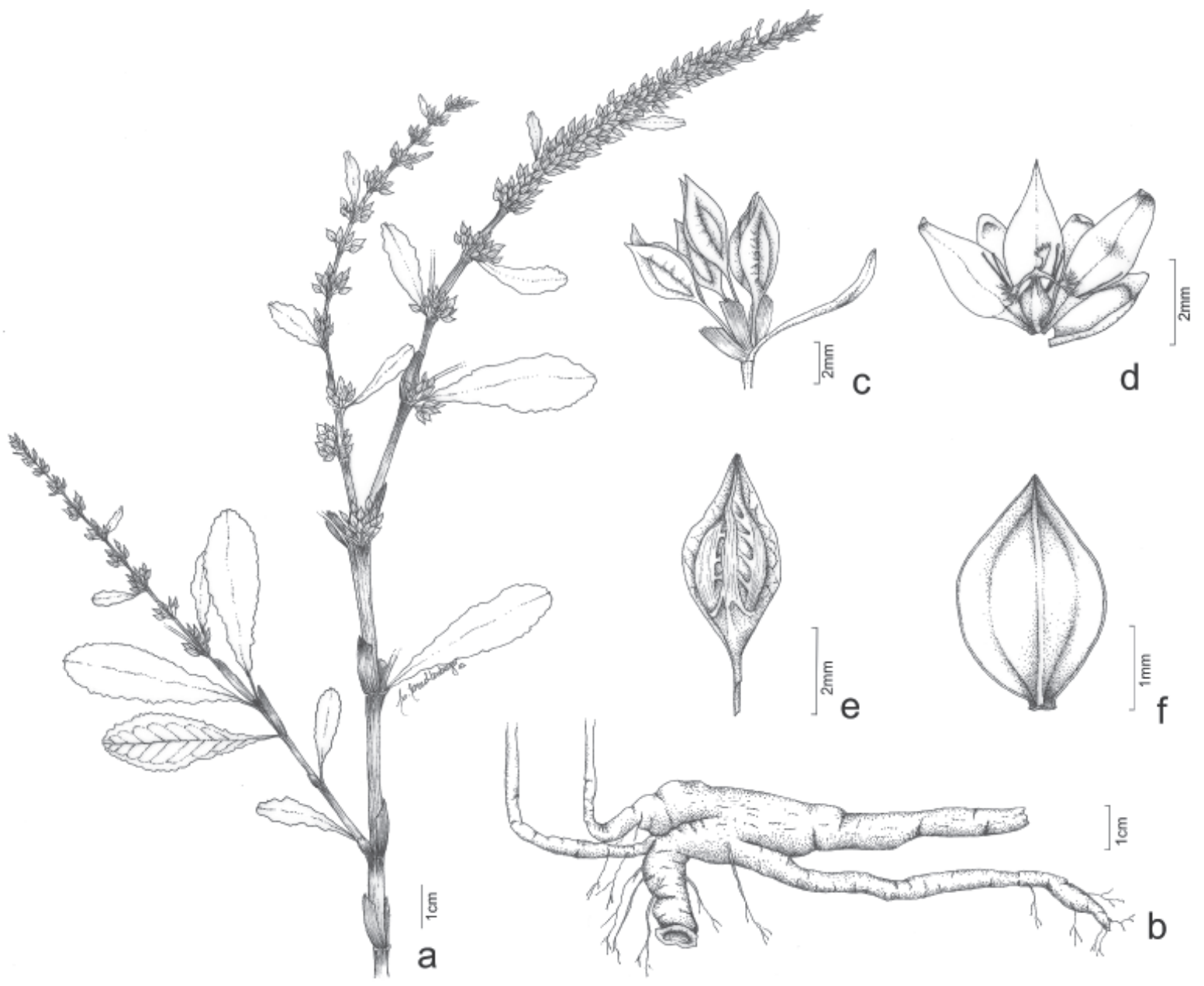

Figura 1. Rumex cuneifolius Campd. a. Ramo. b. Parte do rizoma. c. Parte da inflorescência com flores fechadas e ocréolas. d. Flor pistilada aberta. e. Fruto com perianto. f. Fruto sem perianto (a: Caporal 301; b: Caporal 300; c-f: Caporal 301).

Figure 1. Rumex cuneifolius Campd. a. Branch. b. Part of the rhizome. c. Part of inflorescence with flower buds and ocreolas. d. Pistillate flower opened. e. Fruit with perianth. f. Fruit without perianth (a: Caporal 301; b: Caporal 300; c-f: Caporal 301). 
Nome popular: língua-de-vaca.

Fenologia: floresce e frutifica de dezembro a fevereiro. Distribuição geográfica e ecologia: Peru, Bolívia, Chile, Argentina e Uruguai (Rechinger 1937, Lousley 1953, Cabrera 1967) e Brasil. Introduzida na América do Norte, Europa e Austrália (Rechinger 1937, Mosyakin 2005).

Espécimes de $R$. cuneifolius não foram encontrados nos herbários consultados e até o momento, no Brasil, sua ocorrência foi documentada apenas no Rio Grande do Sul, onde sua origem permanece incerta. A população foi constatada na Cabanha Sobrado Branco, no município de Canguçu a $266 \mathrm{~km}$ de Porto Alegre, na região fitogeográfica da Serra do Sudeste (Fortes 1959), bioma Pampa (IBGE 2005). Na propriedade há áreas de campo nativo submetido a pastejo de ovinos, eqüinos e bovinos, e áreas de mata nativa.

A população amostrada foi observada junto à sede da propriedade, onde associada a $R$. crispus L., atua como invasora da horta. Segundo o Dr. Gilson Moreira, a propriedade pertence a sua família desde o final do século XIX e essas espécies de língua-de-vaca são conhecidas no local desde então, como invasoras de lavouras e hortas domiciliares. De acordo com o mesmo, não há registro quanto a sua utilização alimentícia ou forrageira na região, apenas indícios de uso medicinal por seus antepassados.

Plantas de $R$. cuneifolius são reconhecidas pelas folhas lanceoladas ou oboval-lanceoladas, inflorescências com brácteas foliáceas pouco desenvolvidas ou ausentes e pelos frutos com valvas de margem inteira e calos alongados muito desenvolvidos nas três alas. Assemelha-se a $R$. crispus, podendo as duas espécies ocorrer em populações mistas; difere, no entanto, por apresentar folhas com a base atenuada e frutos com valvas triangulares, enquanto $R$. crispus apresenta folhas com a base obtusa e frutos com valvas ovais ou cordadas.

A taxonomia do gênero Rumex é bastante complexa, considerando-se o alto grau de polimorfismo e de hibridação que sofrem as espécies em ambiente natural (Navajas-Pérez et al. 2005). A maioria das amostras do gênero, provenientes do Brasil, representa antigas coleções que estão em mal estado de conservação, necessitando serem recoletadas e revisadas. É provável que $R$. cuneifolius apresente distribuição mais ampla no Brasil, sendo necessária nova investigação e maior investimento em coleta.

\section{Agradecimentos}

Os autores agradecem ao Prof. Dr. Gilson Moreira, proprietário da Cabanha Sobrado Branco pelas informações e à M.Sc. Caroline Leuchtenberger pela confecção das ilustrações botânicas.

\section{Literatura citada}

Cabrera, A.L. 1967. Polygonaceae. In: A.L. Cabrera (ed.). Flora de la Provincia de Buenos Aires. Coleccion Científica, v. 4. INTA, Buenos Aires, pp. 63-65.

Del Vitto, L.A., Petenatti, E.M. \& Petenatti, M.E. 1997. Recursos herbolarios de San Luis (República Argentina). Primera parte: plantas nativas. Multequina 6:49-66.

Fortes, A.B. 1959. Geografia física do Rio Grande do Sul. Globo, Porto Alegre.

Goleniowski, M.E., Bongiovanni, G.A., Palácio, L., Nuñez, C.O. \& Cantero, J.J. 2006. Medicinal plants from the "Sierra de Comechingones", Argentina. Journal of Ethnopharmacology 107: 324-341.

Holmgren, P.K., Holmgren, N.H. \& Barnett, L.C. 1990. Index Herbariorum. The herbaria of the world. $8 \mathrm{ed}$. New York Botanical Garden, New York.

IBGE (Instituto Brasileiro de Geografia e Estatística). 2005. Mapa de Biomas. Disponível em: http:// mapas.ibge.gov.br/biomas2/viewer.htm (acesso em 9.7.2010).

INTA (Instituto Nacional de Tecnologia Agropecuária). 2003. Plantas silvestres comestibles y condimenticias del NOA. Boletín Desideratum 1(1). Disponível em: http://www.inta.gov.ar/salta/info/boletines/ desideratum/boletin_desideratum1.htm (acesso em 9.7.2010).

Lousley, J.E. 1953. Rumex cuneifolius and a new hybrid. Watsonia 2: 394-397.

Macía, M.J., García, E. \& Vidaurre, P.J. 2005. An ethnobotanical survey of medicinal plants commercialized in the markets of La Paz and El Alto, Bolivia. Journal of Ethnopharmacology 97: 337-350.

Meisner, C.F. 1855. Polygonaceae. In: C.F.P. Martius \& A.W. Eichler (eds.). Flora Brasiliensis. Typographia Regia, Monachii, v. 5, pars 1, pp. 1-59.

Melo, E. 2010. Polygonaceae. In: Lista de Espécies da Flora do Brasil. Jardim Botânico do Rio de Janeiro. Disponível em http://floradobrasil.jbrj.gov.br/2010/FB013735. (acesso em 1.7.2010). 
Melo, E. \& Marcondes-Ferreira, W. 2009. Polygonaceae. In: M.G.L. Wanderley et al. (eds.). Flora Fanerogâmica do Estado de São Paulo. Instituto de Botânica, FAPESP, São Paulo, v. 6, pp.169-193.

Mosyakin, S. 2005. Polygonaceae: 26. Rumex Linnaeus. In: Flora of North America Editorial Committee (eds.). Flora of North America. v. 5. Disponível em: http:// www.fna.org (acesso em 1.7.2010).

Navajas-Pérez, R., Schwarzacher, T., Herrán, R., Rejón, C.R., Rejón, M.R. \& Garrido-Ramos, M. 2005. The origin and evolution of the variability in a Y-specific satelliteDNA of Rumex acetosa and its relatives. Disponível em: http://www.sciencedirect.com (acesso em 16.9.2010).
Rechinger, K.H. 1937. The North American species of Rumex. Publications of the Field Museum of Natural History, Botanical series 17: 3-151.

Rechinger, K.H. 1990. Rumex subgen. Rumex sect. Axillares (Polygonaceae) in South America. Plant Systematics and Evolution 172: 51-192.

Robles, E.C., Argote Q., G. \& LLacho, A.P.G. 2001. Vegetación. Rumex cuneifolius L. Campdera. In: E.C. Robles (coord.). Evaluación de las características y distribución de los bofedales en el ámbito peruano del sistema TDPS. Facultad de Ciências Biológicas U.N.A., Puno, pp. 96-219. 